\title{
Caracterização anatomopatológica da inflamação do espaço interdigital em fêmeas bovinas da raça Girolando
}

\section{Anatomopathological characteristics of the inflammation from interdigital space in bovines females of Girolando breed}

\author{
Rosana Rezende Moraes, ${ }^{*}$ Luiz Antônio Franco Silva, ${ }^{* *}$ Maria Clorinda Fioravanti, ${ }^{* *}$ Luiz Fernando Fróes Fleury, ${ }^{* * *}$ \\ Paulo Henrique Jorge da Cunha, ${ }^{* *}$ Ediane Batista Silva, ${ }^{* * *}$ Patrícia Alessi Teixeira, ${ }^{* * *}$ Liliana Borges Menezes ${ }^{\star * * * *}$
}

\begin{abstract}
Resumo
O presente trabalho teve como objetivo determinar as características histopatológicas da pele do espaço interdigital, em cinco fêmeas bovinas da raça Girolando, apresentando inflamação seguida de fistulação. O experimento foi realizado no período de novembro de 1998 a dezembro de 1999, na Escola de Veterinária da Universidade Federal de Goiás (EV/UFG), utilizando bovinos procedentes de três propriedades rurais do estado de Goiás, criados extensivamente. Os animais foram clinicamente examinados nas propriedades de origem, para a identificação do estágio da doença e, em seguida, encaminhados para o local do experimento. Ao detectar a presença de fístula, as observações clínicas foram interrompidas e, aproximadamente 12 horas após realizou-se a biópsia na pele do espaço interdigital dos membros doentes e saudáveis. As técnicas utilizadas na coloração dos fragmentos para a histopatologia foram: hematoxilina e eosina, vermelho congo, azul de toluidina modificado, Gomori, Gram e Ácido Periódico de Schiff (PAS) modificado. A biópsia do espaço interdigital apresentou na epiderme presença de glóbulos de queratina, acantose e espongiose. Na derme foi observado infiltrado inflamatório predominantemente mononuclear com tendência a formar granuloma e pouca quantidade de mastócitos, não sendo visualizada a presença de fungos. Os achados analisados em conjunto mostram uma inflamação localizada, que é histopatologicamente de caráter crônico, apesar dos sinais clínicos da doença serem agudos ou que é uma resposta inflamatória diferenciada, possivelmente desencadeada por um agente específico.
\end{abstract}

Palavras-chave: bovino, anatomopatológico, afecção podal

\begin{abstract}
This work had as main objective to characterize histopathologic parameters from the tissue of space digital in bovine females that had shoed inflammation with fistulation. The experiment was accomplished in the period of October of 1998 to December of 1999, in the School of Veterinary of the Federal University of Goiás, using bovines coming from three rural proprieties of the State of Goiás, maintained extensively. The animals were clinic examination in the proprieties for identified the stage of the diseases and then transported to the local experiment. The clinic observation was stopped when it was detected lesion in the space interdigital, and after 12 hours it was done the biopsy of the hurted and the healthy space interdigital. The techniques used to stain the fragments to histopathological were: hematoxylin and eosin, congo red, toluidine bleu, Gomori, Gram e Periodic Acid Schiff (PAS). The biopsy of the tissue interdigital revealed in the epidermis presence of keratin globules, achantosis and espongiose. In the derme was observed cellular infiltration with tendency to form granulom and few mast cells, but haven't seen fungi. All the results analyzed showed one localized inflammation, with chronic histopathological characteristics, although the signs were acute or it were one different specific answer, probably caused by specific agent.
\end{abstract}

Keywords: bovine, anatomopathological, foot diseases.

* Médica-veterinária do Ministério da Agricultura - QRSW 01 BI.01 Setor Sudoeste - CEP 70675-100, Brasília, DF. rrmoraes@agricultura.gov.br.

** Professores da Escola de Veterinária da Universidade Federal de Goiás (UFG). Campus II, CP 131, CEP 74001-970 - Goiânia, GO. Brasil lafranco@vet.ufg.br.

*** Professor da Faculdade de Medicina da Universidade Federal de Goiás (UFG).

**** Médica-veterinária autônoma.

*****Aluna do Curso de Mestrado em Ciência Animal da Escola de Veterinária da Universidade Federal de Goiás (UFG). 


\section{Introdução}

As enfermidades podais dos bovinos exercem forte impacto econômico negativo sobre a rentabilidade da pecuária mundial, tanto pela redução na produção de leite, diminuição na fertilidade, redução do peso corpóreo, e alteração na conversão alimentar, quanto pelo aumento nos custos com o tratamento e o descarte prematuro de animais de alto valor zootécnico, podendo até mesmo inviabilizar esse tipo de exploração, caso a prevalência seja alta.

Em determinadas regiões do país avalia-se que as doenças digitais atinjam números significativos. Borges et al. (1992) observaram índices de até $14,17 \%$ de patologias podais em bovinos leiteiros, submetidos a diferentes sistemas de manejo, com maior prevalência de pododermatite séptica e hiperplasia digital. Em um estudo realizado por Molina et al. (1999) na bacia leiteira de Belo Horizonte, utilizando 469 vacas em lactação de 10 propriedades rurais, a prevalência de enfermidades podais foi de $30,28 \pm 4 \%$, sendo que $66,67 \%$ dos casos ocorreram nos membros pélvicos e $33,33 \%$ nos membros torácicos.

As principais perdas econômicas causadas pelas enfermidades do aparelho locomotor são atribuídas ao descarte prematuro dos animais afetados, perda de produtividade com diminuição da produção de leite, perda de peso e redução da fertilidade, além de altos custos dos tratamentos (Baggott e Russel, 1981; Dirksen e Stöber, 1981; Greenough et al., 1981; Rowlands e Lucey, 1986; Weaver, 1988; Groehn et al., 1992; Bargai e Levin,1993; Ramos, 1999). Para Silva (1998), o prejuízo das doenças de casco deve ser contabilizado levando-se em consideração todos os segmentos envolvidos na produção do animal.

Vários fatores estão envolvidos na etiologia das doenças digitais dos bovinos, entre eles: a predisposição genética, especialmente aprumos e ângulos dos paradígitos; o meio ambiente, estado do piso dos currais e sala de ordenha, as pastagens; o manejo, como concentração dos animais e exercícios excessivos; as estações do ano; o clima; e a nutrição. Cada um desses elementos, tomado isoladamente, pode estar na origem do processo morboso. No entanto, vários desses fatores podem agir em interdependência (Dirksen e Stöber, 1981; Corbellini, 1994). Apesar de serem considerados vários fatores predisponentes não se conhece bem o envolvimento desses com a etiologia das diferentes enfermidades de casco. Todavia, o processo infeccioso desencadeia várias alterações no tecido interdigital (Borges e Mársico Filho, 1995). As lesões iniciais da pododermatite infecciosa ocorrem na região interdigital e afetam ambos os dígitos. A pele torna-se edemaciada, hiperêmica, tumefeita e com erosões e em seguida, a inflamação se dissemina para a matriz epidérmica do casco (Carlton e McGavin, 1998).

A pele do espaço interdigital de um bovino saudável possui epitélio recoberto por uma camada considerável de queratina (Blowey et al., 1994), apresenta ainda um número reduzido de células sangüíneas, observando um pequeno infiltrado linfocítico perivascular, sendo os histiócitos, mastócitos e eosinófilos vistos raramente (Boosman et al., 1991). Ao comparar animais doentes e saudáveis, observa-se que em casos recentes de doenças podais ocorre a perda da camada superficial de queratina com o conseqüente espessamento das células do epitélio (Blowey et al., 1994). Histologicamente pode-se ainda observar em animais com enfermidades podais a presença de acantose, paraqueratose e hiperqueratose. Notase também a presença de agregados neutrofílicos e ocasionalmente focos de hemorragia na epiderme. Pequenas arteríolas na derme são usualmente contornadas por agregados de linfócitos, células plasmáticas e ocasionalmente eosinófilos (Boosman, 1990; Weaver, 1994). A arteriosclerose é freqüentemente encontrada, sendo caracterizada pela proliferação da camada íntima e danos às camadas da lâmina elástica interna ocorrendo em muitos casos shunts vasculares (Boosman et al., 1989).

Um outro achado comum nos exames histopatológicos corados pela prata é a presença de espiroquetas invadindo o epitélio, principalmente nos casos de dermatite digital, nesses casos, as colorações de Gram revelam poucas bactérias superficialmente, possivelmente devido à presença de toxinas produzidas pelas espiroquetas que inibem o crescimento das bactérias (Blowey et al., 1994)

O presente trabalho teve como objetivo determinar as características histopatológicas da pele do espaço interdigital, em fêmeas bovinas da raça Girolando, apresentando inflamação seguida de fistulação.

\section{Material e métodos}

Neste estudo observou-se a evolução clínica da inflamação do espaço interdigital em cinco fêmeas bovinas e colheu-se material para exames anatomopatológicos. O experimento iniciou-se no dia em que os primeiros sinais clínicos de inflamação da extremidade do membro foram observados e finalizou-se aproximadamente 12 horas após ocorrer a fistulação na pele interdigital. Nesse momento, os bovinos foram submetidos à biópsia da pele entre os dígitos, dos membros enfermos e correspondente saudável com a finalidade de realizar o exame histopatológico.

A pesquisa foi realizada no período de novembro de 1998 a dezembro de 1999, na Escola de Veterinária da Universidade Federal de Goiás (EV/UFG), utilizando-se bovinos procedentes de três propriedades rurais do estado de Goiás. Os animais foram clinicamente examinados, para a identificação do estágio da doença e, em seguida, encaminhados para a EV/ UFG, onde permaneceram até o momento em que surgiu a fístula na pele do espaço interdigital.

$\mathrm{Na}$ escolha dos bovinos estabeleceu-se que a enfermidade em todos os animais deveria apresentar a mesma evolução clínica, independentemente da propriedade de origem.

Os animais eram da raça Girolando, com idade entre 96 a 120 meses, apresentando número de parições variáveis de dois a quatro, com peso corporal e aptidão semelhantes. Todos os bovinos encontravam-se entre o sexto e o $10^{0}$ mês de pós-parto e eram mantidos em regime de pasto.

A caracterização da inflamação do espaço interdigital fundamentou-se na classificação estabelecida por Silva et al. (1996), Silva (1997), Borges (1998) e Greenough (2000), que consideraram como sinais clínicos a claudicação, o edema e a hiperemia da região ungular, sem haver, no entanto, lesões macroscópicas aparentes na pele do espaço interdigital.

O exame clínico específico dos membros locomotores realizado nos animais, ainda nas fazendas, teve a finalidade de auxiliar na escolha dos bovinos portadores da doença, 
mas sem a presença de fístula. Utilizaram-se aqueles animais que haviam apresentado os sinais da enfermidade entre $12 \mathrm{e}$ 24 horas. Após serem transferidos para EV/UFG, os bovinos foram examinados, diariamente, para detectar o início do processo de fistulação da pele do espaço interdigital.

A biópsia foi realizada aproximadamente 12 horas após 0 membro afetado apresentar fístula na pele do espaço interdigital. Para a realização deste procedimento os animais foram contidos em posição quadrupedal, em bretes apropriados e as extremidades distais higienizadas com água e sabão, a assepsia do local feita com iodo povidine ${ }^{1}$ e a anestesia praticada com cloridrato de lidocaína. ${ }^{2}$ Para remoção do fragmento fez-se a incisão em forma de cunha no espaço interdigital, tanto do membro afetado como do contra-lateral saudável do mesmo animal. Procurou-se colher uma amostra de tecido saudável associado ao comprometido.

O material colhido foi fixado em solução de formalina neutra tamponada a 10\%, em proporção de 20 vezes o volume do fixador em relação ao volume das peças. O material foi clivado 24 horas após a colheita, quando trocou-se o fixador. Os fragmentos aí permaneceram por mais 24 horas, para completar a fixação. Em seguida foram transferidos para pequenas caixas plásticas individuais (unicassetes) e permaneceram estocados em álcool a $70 \%$. Ao final do período de colheita, as amostras foram desidratadas em álcool etílico em série crescente, desde $70 \%$ até álcool absoluto. Posteriormente procedeu-se à clarificação com xilol e inclusão em parafina histológica, com ponto de fusão a $56^{\circ} \mathrm{C}$ (metodologia adotada pelo Laboratório de Patologia da EV/ UFG).

$\mathrm{Na}$ etapa seguinte, os fragmentos foram seccionados a cinco micrômetros em micrótomo rotativo, ${ }^{3}$ utilizando-se navalhas descartáveis. Os cortes obtidos de todos os fragmentos colhidos foram corados pela técnica de hematoxilina e eosina (Luna, 1968), vermelho congo e azul de toluidina modificado (Tarpley et al., 1984) para visualização de células inflamatórias, pela técnica Gomori (Luna, 1968) para a observação da presença de fungos, de Gram para a visualização da flora bacteriana (Luna, 1968) e ácido periódico de Schiff (PAS) modificado, para marcar polissacarídeos e fungos (Laboratório de Histotecnologia do Hospital das Clínicas da Universidade Federal de Goiás). A leitura foi realizada em microscópio óptico ${ }^{4}$ de campo claro.

\section{Resultados}

A avaliação histopatológica dos fragmentos das biópsias dos membros saudáveis dos animais estudados mostrou na coloração de hematoxilina eosina, epitélio espesso característico da região interdigital, com papilas extensas (Figura 1) e tecido linfático difuso com ligeira concentração na região perivascular.

No estudo realizado nos membros que apresentaram a lesão observaram-se, em todos os animais, hiperperceratose e

\footnotetext{
Biocid - Lab. Pfizer Ltda. Guarulhos, SP.

2 Anestésico Local SPV - Schering Plough Veterinária - Rio de janeiro, RJ.

3 Micrótomo rotatitvo - American-Optical ${ }^{\circledR}$, modelo Spencer-820.

4 Microscópio óptico de campo claro - Carl Zeiss ${ }^{\circledR}$, modelo JENEVAL.
}

acantose do epitélio (Figura 2A), presença de glóbulos hialinos de ceratina no tecido córneo do epitélio (Figura 2A) e vacuolização das células epidérmicas das regiões mais superficiais da camada granulosa (Figura 2B). No estrato espinhoso ocorreu consistente espongiose (Figura 2C), na derme, infiltrado inflamatório mononuclear difuso (Figura 2D), principalmente na região papilar (Figura 2E).

No animal número 2 observou-se, na derme, infiltrado inflamatório com predominância de polimorfonucleares muito próximos às áreas de ulceração e necrose do epitélio: entretanto, nas camadas mais internas do epitélio observouse a diminuição dos polimorfonucleares predominando os mononucleares. Na derme do animal número 4 notou-se edema de papilas (Figura 2F), congestão e hemorragia, além de hipertrofia da parede das artérias com estenose da luz (Figura 2G). O animal 5 apresentou infiltrado perivascular misto com grande quantidade de eosinófilos. $O$ infiltrado inflamatório encontrado nos cortes das biópsias dos membros com lesão mostrou uma tendência a formar granulomas. A fibroplasia da derme também foi um achado freqüente.

$\mathrm{Na}$ coloração vermelho congo azul de toluidina modificada observaram-se poucos mastócitos, tanto nos membros controles como nos membros lesionados (Figura $2 \mathrm{H}$ ).

No PAS para fungos os controles e os doentes foram negativos. Os glóbulos de ceratina observados na derme mostraram-se PAS positivos. Na coloração de Gram não se observou a presença de bactérias, tanto nos cortes histológicos do tecido interdigital lesado como nos sem lesão.

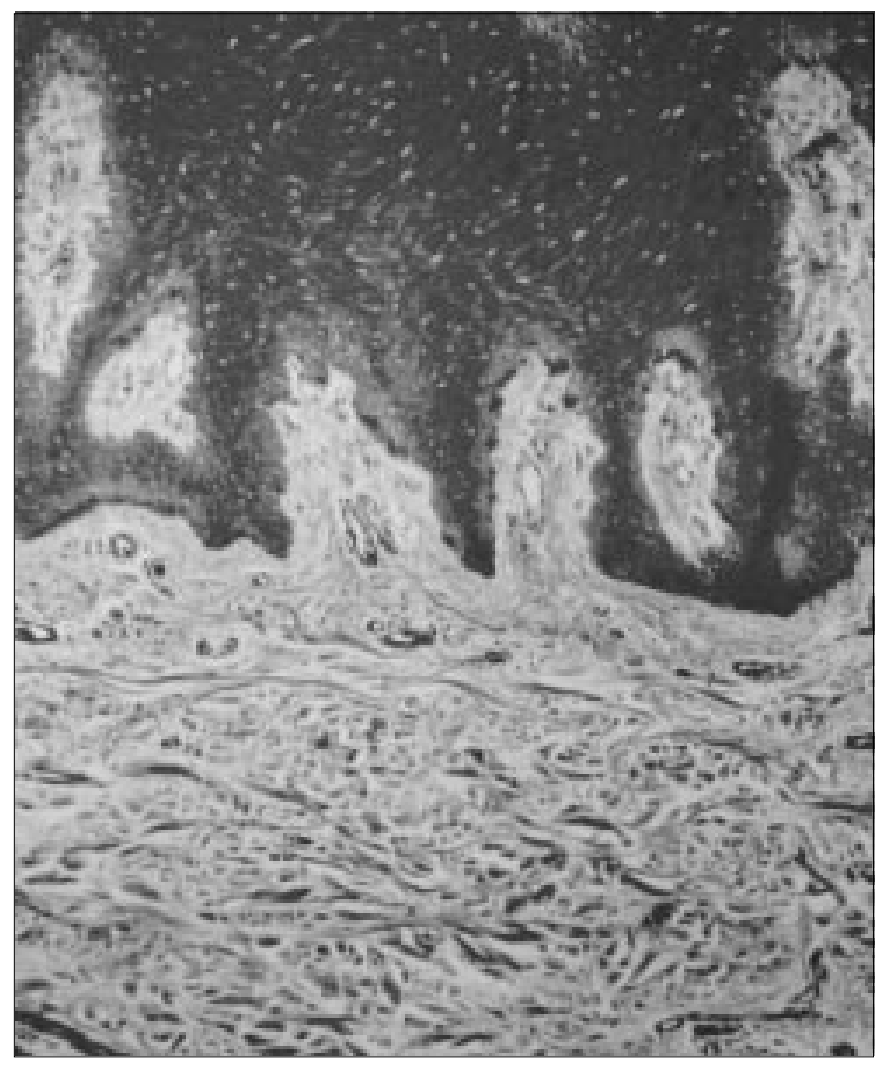

Figura 1: Tecido interdigital normal, mostrando epitélio espesso, papilas extensas e derme sem infiltrado inflamatório. HE, 50X. 

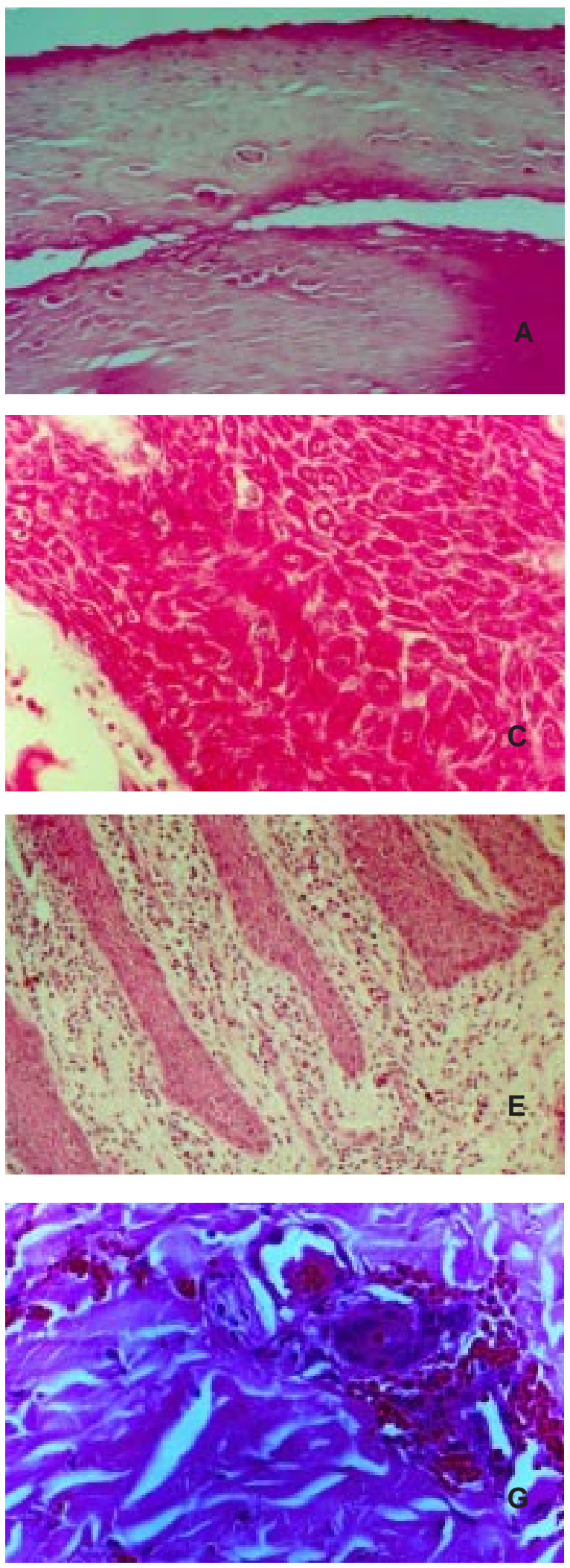
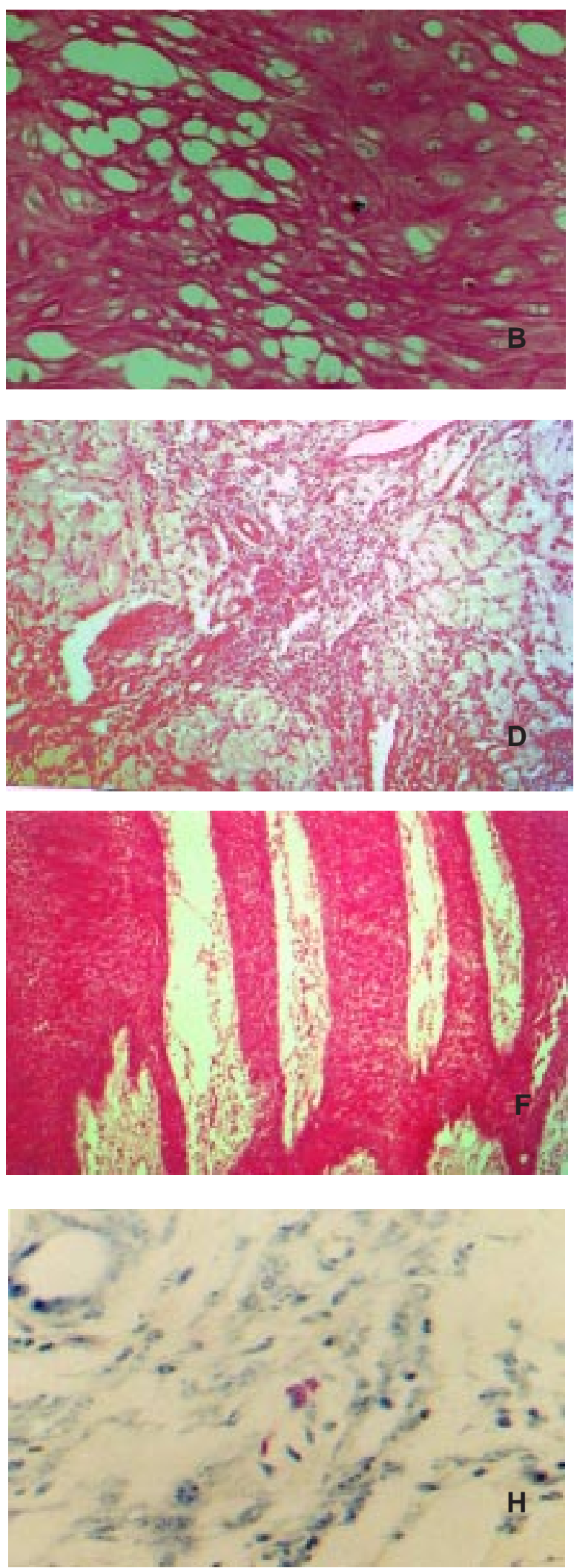

Figura 2: A) Hiperceratose, acantose e presença de glóbulos hialinos de ceratina no tecido córneo do epitélio. HE, 50X. B) Vacuolização das células do estrato espinhoso da epiderme. HE, 100X. C) Espongiose das células do estrato espinhoso da epiderme. HE, 100X. D) Infiltrado inflamatório predominantemente mononuclear na derme. HE, 50X. E) Infiltrado inflamatório mononuclear localizado principalmente na região papilar da derme. HE, 100X. F) Presença de edema na derme especialmente na região papilar. HE, 50X. G) Hipertrofia da parede da artéria com estenose da luz (seta). HE, 100X. H) Presença de mastócitos na derme (seta). Vermelho congo azul de toluidina modificado, 100X. 


\section{Discussão e conclusões}

Os achados anatomopatológicos foram de grande significado para o experimento, apesar de não possibilitarem o estabelecimento do diagnóstico definitivo em relação à gênese da lesão da inflamação do espaço interdigital.

O exame anatomopatológico do material colhido no espaço interdigital dos membros locomotores saudáveis apresentou epitélio com epiderme espessa, papilas alongadas e bem projetadas, tecido linfático difuso com ligeira concentração perivascular e pouca ocorrência de mastócitos (Figura 1). Tais dados concordam com citações de Maclean (1965), Edwards (1982) e Boosman et al. (1991) que descreveram a ocorrência de uma leve infiltração linfocitária perivascular além dos mastócitos serem raramente visualizados nas regiões distais dos membros de bovinos saudáveis. Os autores citaram ainda a ocorrência de um arranjo em forma de paliçada das células do estrato basal ao longo da membrana basal.

A hiperceratose paraceratótica foi observada em todas as biópsias do tecido lesado (Figura 2A). Segundo Carlton e McGavin (1998), a hiperceratose paraceratótica é um aumento de espessura do estrato córneo contendo remanescentes nucleares, estando associada à redução na espessura da camada granular. Weaver (1994) cita que a hiperceratose está envolvida nas inflamações supurativas da epiderme nos casos de dermatites e papilomatoses digitais. A presença da hiperceratose paraceratótica nos animais estudados neste experimento sugere um processo inflamatório. Edwards (1982) e Lischer e Ossent (2002) descreveram que em casos de laminite ocorre um aumento desorientado das células do estrato germinativo e espinhoso; entretanto, nestes casos ocorre desaparecimento parcial ou total da queratina.

Os glóbulos de queratina verificados nas camadas superficiais da camada granulosa (Figura 2A) foram citados por Boosman (1990) e Boosman et al. (1991) em biópsia de pele interdigital de bovinos com laminite. No PAS essas estruturas foram positivas, sendo, portanto, substâncias glicoproteicas. Pela localização e pela composição protéica da queratina, tais alterações são sugestivas de possível deficiência na maturação da queratina. Segundo Blowey et al. (1994), a perda da camada superficial de queratina estimula a proliferação e hiperplasia da epiderme, explicando a deficiência na maturação da queratina como a hiperceratose.

A acantose (Figura 2A) encontrada em dois dos animais e a espongiose (Figura $2 \mathrm{C}$ ) em três dos animais foram também citadas por vários autores em casos de dermatite digital, papilomatose digital e laminites (Boosman, 1990; Boosman et al., 1991; Blowey et al., 1994; Weaver, 1994; Van Amstel et al., 1995; Dermikan et al., 2000).

\section{Referências}

BAGGOTT, D.G.; RUSSEL, A. M. Lameness in cattle. Brit. Vet. J., v. 137, n. 1, p. 113-132, 1981.

BARGAI, U.; LEVIN, D. Lameness in the Israeli dairy herd - a national survey of incidence, types, distribution and estimated cost (first report). Irs. J. Vet. Med., v. 48, p. 88-91, 1993.

BLOWEY, R. W.; DONE, S. H.; COOLEY, W. Observations on the pathogenesis of digital dermatitis in cattle. Vet. Rec., v. 135, p. 115-117, 1994.
Nos animais aqui estudados, o infiltrado inflamatório foi predominantemente mononuclear, lembrando uma reação granulomatosa (Figuras 2D e 2E). Mesmo no caso onde o infiltrado foi polimorfo em regiões superficiais do epitélio, próximas dos locais onde havia úlcera e necrose, ao aprofundar na derme, prevaleceu o infiltrado mononuclear. Blowey et al. (1994) descreveram que, em casos estabelecidos de dermatite digital, ocorre uma reação neutrofílica na derme com a presença de infiltrado inflamatório difuso, composto também por células como os monócitos e linfócitos. Rebhun et al. (1980) citaram também que a ocorrência de infiltrados inflamatórios neutrofílicos acontece nos casos de papilomatose interdigital.

Em um dos animais avaliados ocorreu infiltrado perivascular com grande quantidade de eosinófilos. Segundo Carlton e MacGavin (1998), as infiltrações inflamatórias perivasculares eosinofílicas são sugestivas de hipersensibilidade; entretanto, esse achado ocorreu em apenas um animal. Para Hargis (1990), nas reações de hipersensibilidade é freqüente a presença de inflamação perivascular, edema e presença de inúmeros mastócitos e eosinófilos.

Alterações semelhantes a shunts arteriovenosos foram encontradas na lesão de um animal que apresentou hipertrofia da parede alveolar com estenose da luz (Figura 2G). Boosman et al. (1989), Weaver (1994), Van Amstel et al. (1995) e Hoblet e Weiss (2001) também descreveram a presença desse achado nos casos de laminite.

Observou-se em um animal a presença de edema (Figura $2 \mathrm{~F})$, indicando, possivelmente, um distúrbio circulatório. Boosman (1990), Boosman et al. (1991), Blowey et al. (1994), Weaver (1994) e Van Amstel et al. (1995), afirmaram que, nas enfermidades podais, as alterações vasculares acompanhadas de hemorragia e edema são comuns.

Apesar de terem sido utilizadas colorações especiais, não foram detectados fungos e bactérias. Entretanto, alguns autores como Blowey et al. (1994), Van Amstel et al. (1995) observaram bactérias do tipo espiroquetas associadas aos casos de dermatite digital.

A análise histopatológica da pele do espaço interdigital logo após a fistulação, em fêmeas bovinas da raça Girolando portadoras de inflamação, caracterizou-se por apresentar glóbulos de queratina, acantose e espongiose na epiderme, infiltrado inflamatório predominantemente mononuclear com tendência a formar granulomas e pouca quantidade de mastócitos, não sendo visualizada a presença de fungos.

Os achados analisados em conjunto mostram uma inflamação localizada, que é histopatologicamente de caráter crônico, apesar dos sinais clínicos da doença serem agudos ou que é uma resposta inflamatória diferenciada, possivelmente desencadeada por um agente específico.

BOOSMAN, R. The influence of calving and puerperium on clinical and histophatologic changes associated with laminitis and sole ulceration in a group of first-calving cows. J.Vet. Med. A., v. 37, p. 513-519, 1990.

BOOSMAN, R.; KOEMAN, J.; N. A. P. R. Histopathology of the pododerma in relation to age and chronic laminitis. J. Vet. Med. A., v. 36, n. 6, p. 438-446, 1989.

BOOSMAN, R.; NÉMETH, F.; GRUYS, E. Bovine laminitis: clinical aspects, pathology and pathogenesis with reference to acute equine laminitis. Vet. Quart., v. 13, n. 3, p. 163-171, 1991. 
BORGES, J. R. J.; PITOMBO, C. A.; SANTIAGO, S. S.; RIBEIRO, P., RONCONI, M. A. Incidência de enfermidades podais em bovinos leiteiros submetidos a diferentes sistemas de manejo. Arq. Esc. Med. Vet.UFBA, v. 15, n. 1, p. 34-42, 1992.

BORGES, J. R. J.; MÁRSICO FILHO, F. Podologia bovina. Departamento de Patologia e Clínica Veterinária, Universidade Federal Fluminense, 1995.

BORGES, N. C. Caracterização do fluido ruminal e dos parâmetros clínico- laboratoriais de bovinos com pododermatite. Goiânia, 69 f. Dissertação (Mestrado). Escola de Veterinária, Universidade Federal de Goiás, 1998.

CARLTON, W. W.; McGAVIN, M.D. Patologia Veterinária Especial. 2. ed. Porto Alegre: Artmed, 1998, p. 672.

CORBELLINI, C.N. Factores nutricionales de riesgo para las afecciones podales. In: Enfermedades podales del bovino. Jornada-Taller para médicos veterinarios. Navarro, p. 1-5, 1994.

DERMIKAN, I.; MURRAY, R. D.;CARTER, S. D. Skin diseases of the bovine digit associated with lameness. Veterinary Bulletin, v. 70, n. 2, p.149-171, February, 2000.

DIRKSEN, G.; STOBER, E. M. As afecções dos cascos dos bovinos: melhor prevenir que curar. Hora. Vet., v. 1, n. 3, p.13-19, 1981.

EDWARDS, G. B. Acute and subacute laminitis in cattle. Vet. Annual., v. 22, p. 99-106, 1982.

GREENOUGH, P. R.; MAcCALLUM, F. J.;WEAVER, A. D. Lameness in cattle. 2. ed., Bristol: Wright. Scientechnica, 1981, 471 p.

GREENOUGH, P. R. Diseases of the feet pf dairy cows. Congresso Brasileiro de Cirurgia e Anestesiologia Veterinária. Goiânia, 1-6 de outubro de 2000, p.1-21.

GROHEM, J. A.; KANEENE, J. B.; FOSTER, D. Risk factors associated with lameness in lacting dairy cattle in Michigan. Preven. Vet. Med., v. 14, p. 77-88, 1992.

HARGIS, A. Sistema tegumentar. In: THOMSON, R.G. Patologia veterinária especial. São Paulo: Manole, 1990. Cap.1, p.1-77.

HOBLET, K. H.; EWISS, W. Metabolic hoof horn disease: claw horn disruption. In: ANDERSON, D. E. Lameness. The Veterinary clinics of North America: food animal pratice, v. 17, n.1, March, p. 111-128, 2001.

LISCHER, C. J; OSSENT, P. Pathogenesis of sole lesions attributed to laminitis in cattle. XII INTERNATIONALSYMPOSIUM ONDISORDERSOF THE RUMINANT DIGIT. Orlando- USA. Proceedings... 2002. p. 82-89.
LUNA, L. G. Manual of Histologic Staining Methods of the Armed Forces Institute of Pathology, 3. ed. New York: McGraw-Hill, 1968. $258 \mathrm{p}$.

MACLEAN, C. observation on acute laminitis of cattle in south hampshire. Vet. Rec., v. 77, n. 24, p. 662-672, 1965.

MOLINA, L. R.; CARVALHO, A. U.; FACURY FILHO, E. J.;FERREIRA, P. M., FERREIRA, V. C. P. Prevalência e classificação das afecções podais em vacas lactantes na bacia leiteira de Belo Horizonte. Arq. Bras. Med. Vet. Zootec., v. 51, n. 2, p. 149-152, 1999.

RAMOS, L. Avaliação econômica dos efeitos da pododermatite sobre a reprodução e produção dos bovinos. 1999. 113 f. Dissertação (Mestrado)-Escola de Veterinária da Universidade Federal de Goiás. REBHUN, W.C.; PAYNE, R.M.; KING, J.M.; WOLFE, M.; BEGG, S.N. Interdigital papillomatosis in dairy cattle. J.A.V.M.A., v. 177, n. 5, p. 437440, 1980.

ROWLANDS, G. J.; LUCEY, S. Changes in milk yield in dairy cows associated with metabolic and reproductive disease and lameness. Preventive Vet. Med., v. 4, p. 205-221, 1986.

SILVA, C. A. Identificação e isolamento do Dichelobacter nodosus e do Fusobacterium necrophorum de bovinos portadores de pododermatite, relações com a etiopatogenia, dados edafoclimáticos e avaliação do tratamento. 1997. 81f. Dissertação (Mestrado)—Escola de Veterinária, Universidade Federal de Goiás.

SILVA, L. A. F. Haja casco para tanta doença. Produtiva. v. 3, n. 22, p. 17-21, 1998.

SILVA, L. A. F., SILVA, C. A., FIORAVANTI, M. C. S., ARAÚJO, E. G., VIEIRA, D., BORGES, N. C. Estudo comparativo entre três tratamentos cirúrgicos para duas formas de apresentação clínica da pododermatite bovina. In: Congresso Brasileiro de Medicina Veterinária, XXIV. Anais..., Goiânia, 1996, p. 34.

TARPLEY, J.E.; MESCHTER, C. L., TYLER, D. E Modified congo-red acidified toluidine blue strain: a new technique for simultaneous staining of eosinophils and mast cells in paraffin tissue section. J. Histotec., v. 7, p. 141-142, 1984.

VAN AMSTEL, S. R.; VAN VUUREN, S.; TUTT, C. L. C. Digital dermatitis: report of an outbreak. S. Afr. Vet. Ass., v. 66, n. 3, p. 177-181, 1995.

WEAVER, A. D. Cattle foot problems part 1 : Introduction and interdigital skin disease. Agri Pract. Podiatry, v. 9, n. 1, p. 34-38, 1988.

WEAVER, A. D. Digital papillomatosis and digital dermatitis in cattle. Vet. Annual, v. 34, p. 20-27, 1994. 